\title{
Unibertsitateko irakasleen profesionalizazio baterantz: azterketa teorikoa ${ }^{1}$
}

\author{
Alba Madinabeitia Ezkurra \\ Idoia Fernández Fernández. \\ Hezkuntzaren Teoria eta Historia Saila \\ Hezkuntza, Filosofia eta Antropologia Fakultatea \\ Euskal Herriko Unibertsitatea UPV/EHU
}

DOI: $10.1387 /$ tantak.17869

GAKO-HITZAK: Hezkuntzaren kalitatea, irakaskuntza-hobekuntza, hezkuntzaren garapena, ikaskuntza, erakundearen aldaketa, unibertsitate-hezkuntza.

\section{SARRERA}

Milurte honetako lehendabiziko hamarkadan beregainki gertatu diren aldaketa politikoek, sozioekonomikoek eta kulturalek goi-mailako hezkuntzan eragin zuzena izan dute. Horren ondorioz mundu akademikoaren estamentu ezberdinetako eskakizunak idazpuru komun batean laburbilduz joan dira: irakaskuntzaren eta ikaskuntzaren kalitatea hobetzeko premia, alegia (Barr \& Tagg, 1995; Clifford, 1999; Zimmerman, 2002). Gure testuingurutik begiratuta, mugimendu horien erakusgarri behinena Boloniako prozesua izan da (Declaration, 1999; Eurydice, 2007; Fell, Haines \& Denicolo, 2009). Izaera politikoa duen erabaki hau, motzean zein luzean, europar unibertsitateen irakaskuntza eta ikaskuntza egiturak aldatzeko bokazioz eta kalitatez hornitzeko jaio eta garatu da, ondare gisa, beste askoren artean, galdera interesgarria utzi duena: zer da unibertsitatean irakaslea izatea? Gertutik, maila anitzeko aldaketari datxekion irakasleen lanak beharko lukeenaren oinarriak finkatzearekin batera, gaion inguruko eztabaida ere biziagotu du (Norton, Sonnemann \& Cherastidtham, 2013).

1 Artikulu hau Euskal Herriko Unibertsitateak (UPV/EHU) diruz lagundutako IkasGura (GIU 14/08) ikerketa talde kontsolidatuak egindako lanaren emaitza da, eta «Hezkuntza, Kultura eta Gizartea» izena duen Prestakuntza eta Ikerkuntza Unitatearen (UFI 11/54) barruan garatu da. 
Egile desberdinen arabera, unibertsitatea, honezkero, ezagutzaren jendartearen baitako eszenatoki sozial arazotua eta aldakorra bihurtu zaigu (Barnett, 1994; Hargreaves, 2003; Välimaa \& Hoffman, 2008), zeinean goi-mailako hezkuntzaren kalitatea hobetzeko politikek baitezpadako garrantzia bereganatzen duten. Kalitatearen hobekuntza politikoki gauzatzen bada, praktikoki, nazioarteko gobernuen eta instantzien eskutik gauzatzen da. Maila ideologikoari dagokionez ikaskuntza soziokulturalak eta konstruktibistak jarraitzen dituzten teoria zehatzekin batera ematen da -nabarmenki, aldaketa pedagogikoaren entseina modura agertzen direnak(Jonassen, 1999; Kolb \& Kolb, 2005; Ramsden, 2003). Hau guztia, hiru fenomenoek markatutako garai batean ari da jazotzen, hain zuzen ere, teknologia berriek ezagutzarako sarbidean aurrekaririk gabeko abaguneak baliatzen dituztenean, ikasleen aniztasun etnikoak eta kulturalak hazten doazen testuinguruan eta irakasleek ulermen zein trebetasun berriak bereganatu behar dituztenean.

Baldintza hauetan, unibertsitateak orokorki eta pertsonal akademikoak bereziki, ikasleen ikaskuntza indartzeko eta berau ahalbidetzeko nozio berriak garatuz joan dira, ikaskuntza esperientziak aberastea jomuga izanez, beti (Hanbury, Prosser \& Rickinson, 2008; Knapper, 2003).

Ikasleen ikaskuntza hobetzea azken helburua den honetan, begirada irakaskuntzara zuzentzea ekidinezina dirudi, nolanahi ere, bi elementuen arteko erlazioa esklusiboa ez baina estua badela ulertzen denean. Arrazoi hau dela medio, gaur-gaurkoz unibertsitateko irakasleriaren hobekuntza, trebakuntza, gaurkotzea edota formazio pedagogikoa gailendu da hezkuntzaren kalitatea hobetzeko ardatz nagusienetakoa bailitzan. Bibliografia anglosaxoiak, bide batez esanda, luzaz aztertu izan du ahotan darabilgun gaia, eta hainbat izendapen erabiltzen ditu formazio kontzeptu hauei erreferentzia egiterako orduan: faculty development, academic development eta educational development, esaterako. Agian interesgarria izan daiteke gogoratzea, termino hauetako bakoitzari esleitutako esanahia modu nahasian agertu ohi dela, beraz, fenomeno hau zorrozki atzemateko definizio hertsi eta adiera bakarrekorik ez da, tamalez. Euskaraz zein espainolez, kasu, ideia hauek nolabait barnebiltzen dituen hitza 'formazioa/formación' da. Hau esanda eta gure jardunean hain ohikoa ez dela jakin arren, artikulu honetan irakasleriaren garapenaz mintzatzea hobetsiko dugu. Arrazoien artean lehendabizikoa, nazioarteko literaturan - faculty development- esanahi corpus zabalena duelako, eta bigarrena, kontzeptuaren analisiak berak dagokion terminologia aniztuko duelako. Bai euskaraz bai espainolez gailentzen den kontzeptua aberastea ekar dezakeelakoan, noski.

Hortaz, artikulu honetan unibertsitateko irakasleriaren garapena (IGa) izango dugu hizpide, oharkabean pasa gabe, eboluzio eta emaitza ezberdinak izan dituen diseinu eta praxi amalgamari so egiten diogula. Edozelan ere, eredu teorikoen, testuinguru akademikoaren eta afera horretan erabilitako baliabideen mendekoa izan da IGa (Day, 2005; Norton et al., 2013). 
Eskuartean, beraz, hamaika ertz dituen eztabaidagaia, unibertsitateko ikasleen ikaskuntza hobetzeko garrantzi handia aitortua duen lanabesa.

Unibertsitateko irakasleriaren garapena kontzeptuaren inguruko analisi sistematikoa burutzea - eta bere esanahien gainean argia ipintzea - da lan honen helburu nagusia. Gure zeregina beraz, IGa gako teorikoetan irudikatzea izango da, denboran zehar kontzeptuan gertatu izan diren aldaketen eta jarraipenen azterketa eginaz. Aztergai honi heltzeko bi galdekizun handiren biran egituratu dugu lana. Lehenik eta behin, goi-mailako hezkuntzan IGaz zer ulertzen den galdegin dugu, eta lan hori taxutzeko, autore ezberdinek kontzeptuaren inguruan emandako definizioak aztertzeaz batera, horiei esleitutako esangurak sistematizatuko ditugu. Bigarrenik, esanahi hauek sortu ziren testuinguru sozio-historikoan tokitu eta artikulatuz joan ziren ikerketa zientifikoen emaitzak arakatuko ditugu. Artikulazio analisi hau hiru ardatzetan banatuko da: a) IGaren sorrera unibertsitatean eta kontzeptuaren estreinako konfigurazioak; b) goi-mailako hezkuntzako IG estrategiek zuten inpaktuaren neurketa-agerraldia, zeinean arreta modu berezian enfasi instituzional zein erakundekoan ipiniko dugun; eta c) hezkuntzaren garapena edo educational development kontzeptua, IGaren eremuan esplorazio sintesi berria dena.

\section{IRAKASLERIAREN GARAPENA KONTZEPTUA GOI-MAILAKO HEZKUNTZAN: POLISEMIAK ETA SINTESIAK}

Irakasleriaren garapenaz ulertzen dena aztertu baino lehen, aipamen azkarrerako beta hartu nahiko genuke, izan ere, kontzeptura egindako lehenengo hurbilpenak ez du zalantzarako tarterik uzten: ez da existitzen kontzeptuaren ulermen unibertsalik, ezta bere adieraren interpretazio bakar eta baliozkorik ere. Kontzeptuari lotutako polisemia ez da soilik unibertsitate eremuan ematen, izatez ezaugarri nabaria bada, IGaren lehendabiziko garapen-esparrua izan den maila ez unibertsitarioan ere (García-Gómez, 1999; Imbernón, 1994; Marcelo eta Vaillant, 2010).

Atal honetan zehar, terminoaren zenbait jatorrizko definizio aztertuko dugu, bai eta proposamen abangoardista bat ere - dagoeneko 90eko hamarkadaren bukaeran - hurbilpen barne-hartzaile eta zabaletik dimentsio ezberdinak integratzen dituen iradokizuna, hain justu.

IGaren definizioak arakatzeko hiru irizpideei lotu gatzaizkio, ekarpen esanguratsuen kopuru mugatua aukeratu ahal izateko: bata, artikuluak ERIC eta JSTOR datu-base zientifikoetan erregistratuta egotea, eta bi, artikuluon aipamen-adierazlea; biak zein biak literatura zientifikoan estaldura zabala dutenaren seinale. Hirugarrena irizpide kronologikoa, hots, 70eko hamarkadatik gaur egunera arte IGaren inguruan izan diren ulermen ezberdinak determinatzea ahalbidetzen duelako (ikus 1. taula). 
1. taula

Unibertsitateko IGaren jatorrizko definizioen sekuentzia kronologikoa 1975 ez geroztik gaurdaino zenbait ekarpen garrantzitsu

\begin{tabular}{|c|c|}
\hline Autorea & Definizioa \\
\hline Gaff (1975) & $\begin{array}{l}\text { Faculty development in higher education as a those activities that } \\
\text { help teachers improve their instructional skills, design better curric- } \\
\text { ula, and/or improve the organizational climate for education. }\end{array}$ \\
\hline Francis (1975) & $\begin{array}{l}\text { Faculty development as a process which seeks to modify the atti- } \\
\text { tudes, skills, and behavior of faculty members toward greater com- } \\
\text { petence and effectiveness in meeting student needs, their own needs, } \\
\text { and the needs of the institution. }\end{array}$ \\
\hline Centra (1978) & $\begin{array}{l}\text { Faculty development refers to that broad range of activities that insti- } \\
\text { tutions use to renew or assist faculty in their roles. }\end{array}$ \\
\hline $\begin{array}{c}\text { Sheets \& Schwenk } \\
\text { (1990) }\end{array}$ & $\begin{array}{l}\text { Faculty development includes initiatives designed to improve the } \\
\text { performance of faculty members in teaching, research and adminis- } \\
\text { tration. }\end{array}$ \\
\hline $\begin{array}{c}\text { Bland et al., } \\
\text { (1990) }\end{array}$ & $\begin{array}{l}\text { Faculty development is a planned program to prepare institutions } \\
\text { and faculty members for their academic roles, including teaching, } \\
\text { research, administration, writing and career. }\end{array}$ \\
\hline Lewis & $\begin{array}{l}\text { Faculty development had evolved into a more expansive term meant } \\
\text { to encompass three key areas of effort: personal development (self- } \\
\text { reflection, vitality, and growth), instructional development (course } \\
\text { and student-based initiatives), and organizational development } \\
\text { (program, departmental, and institution-wide efforts). }\end{array}$ \\
\hline $\begin{array}{c}\text { Wilkerson \& Irby } \\
\text { (1998) }\end{array}$ & $\begin{array}{l}\text { Faculty development as a tool for improving the educational vitality } \\
\text { of our institutions through attention to the competencies needed by } \\
\text { individual teachers and to the institutional policies required to pro- } \\
\text { mote academic excellence. }\end{array}$ \\
\hline Hicks (1999) & $\begin{array}{l}\text { Academic development as the provision of pedagogically sound and } \\
\text { discipline relevant development for academic staff across the broad } \\
\text { spectrum of disciplines present within a university so as to impact ef- } \\
\text { fectively on student learning. }\end{array}$ \\
\hline Bligh (2005) & $\begin{array}{l}\text { The principal purpose of faculty development is to improve prac- } \\
\text { tice. We use faculty development to manage change and to develop } \\
\text { strengths and skills as well as organizational capacities and culture. } \\
\text { This is achieved through changes in the ways people think about } \\
\text { what they do and in changes to what they do in their works. }\end{array}$ \\
\hline
\end{tabular}

Iturria: Ekoizpen propioa. 
Definizioen aniztasuna agerikoa den arren, lehenengo berrikusketa batek argibideak ematen ditu, adierazpen guztiek izendatzaile komuna dutela baieztatzeko. Hots, denek bilatzen dute goi-mailako hezkuntza instituzioen irakaskuntza-ikaskuntza prozesuen kalitatea hobetzea, eta, hein bertsuan prozesu, ekintza edota teknika multzoen bidez, unibertsitateko irakasleengan eragina izatea (Land, 2004; Madinabeitia eta Fernández, 2015; Macdonald, 2002; McLean, Cilliers \& Van Wyk, 2008; Professional and Organizational Network in Higher Education (POD), 2007; Sorcine1li, Austin, Eddy \& Beach, 2005). Hortaz, kasu guztietan irakasleei zuzendutako ekintzez dihardute, horiek direla medio, irakasleaz haraindiko eremuan intzidentzia eduki dezaketela ulertua, ikasleen ikaskuntza bezalako eragin-guneetara iristea, hain zuzen.

Definizioen analisitik bigarren egiaztapen bat eratortzen da. Honakoa, IGaren eraginaz hitz egitean autoreek egiten dituzten interpretazioak bateraezinak dira baina bi enfasi nagusien artean mugitzen direla atzeman daiteke: maila indibidualekoa bata, eta maila instituzional edota erakundekoa, bestea.

Maila indibidualari dagokionez esan dezakegu badirela autore batzuk arreta irakasleengan soilik jartzen dutenak, hau da, irakasleak hobekuntzaren helmuga bakar gisa nabarmentzen dutenak (Sheets \& Schwenk, 1990). Enfasi hau kontzeptuaren sorreran bertan agertu zen eta gaur egunera arte garapen proposamen ugariren euskarrian mantendu den ikuskera da. Ideia arketipiko honetan, funtsean, irakasle norbanakoa diziplinazko ezagutzan aditua izateaz gain, trebetasun pedagogiko zehatzak bereganatu behar dituela irudikatzen da (Hubbard \& Atkins, 1995). Trazu lodian, badirudi definizio mota hauek zera interpretatzen dutela: unibertsitateko irakasleak euren diziplinetan adituak izan daitezen ziurtatuz eta oinarrizko ezagupen pedagogikoekin dohatuz, unibertsitateko irakaskuntzaren kalitatea hobetuko litzateke. Izatez, nagusiena eta hedatuena den kontzepzioa bada ere, ez da bakarra izan.

Maila instituzionalari dagokionez, 70eko hamarkadaren data goiztiarretan bertan aurki daitezke IGaren intzidentzia maila honetaraino zabaltzen zuten definizioak ere, jakina, kontzeptuan ñabardura esanguratsuak erantsiz. Gaff-en (1975) definizioa horren adibide argia da. Autore estatubatuar honek adierazten duenez, IGak irakaslearen gaitasun indibidual jakin batzuk trebatzera bideratuta egon behar du baina, pausu bat haratago eman eta irakasleaz gaindiko mailaren garrantzia azpimarratzen du. Agerian, curriculumaren diseinua edota giro instituzionala hobetzeak hezkuntzari lekarkiokeen garrantziaren defentsa. Ildo beretik lerrokatzen dira beste zenbait autorek ere, irakasleriaren kontzepzio, trebetasun eta praktiken hobekuntzan indarra ipiniaz, baina baita IGak eragin behar duen alor global zabalagoari ikusgarritasuna emanez (Bland, Schmitz, Stritter, Henry \& Aluise, 1990; Centra, 1978; Francis, 1975; Hicks, 1999; Lewis, 1996; Steinert, 2000; Wilkerson \& Irby, 1998). Alor zabal hau, besteak beste, erakundeko giroa, bizitasuna, kultura instituzionala, eta baiki, ikasleen ikaskuntzaren eraginkortasuna hobetzean datza. Finean, autore hauek esaten 
dutena da irakaskuntzaren eta ikaskuntzaren hobekuntza, irakasleriaren iniziatiben batuketa baino zerbait gehiago dela eta alde horretatik beharrezkoa dela indibiduala den eremu horretatik haratago joatea.

Autoreek IGa deskribatzen dutenean hirugarren egiaztapen bat gaineratzen dute, hain justu, unibertsitateko irakasleak rol akademiko ezberdinak betetzen dituzten pertsonak badirela. Espreski, irakasleek garatu behar dituzten rol guztiak sostengatzen dituzten IG kontzepzioei egiten zaie erreferentzia, besteak beste, irakaskuntza, ikerkuntza, administrazioa, idazkuntza zientifikoa eta ibilbide profesionalaren kudeaketa barne biltzen dituztenak. Figura horiek guztiak, faculty, edo itzulpen behartuan nahi bada, «akademiko» hitz gakoan aterpetuta leudeke (Boyer, 1990; Brew, 2010; Taylor \& Canfield, 2007).

Azken batez, IGa aztergai dugunean komeni da, gutxienez bi garapen eremu integratzen dituen kontzeptu zabal gisa definitzea. Batetik, irakaskuntza trebetasunen eguneroko jardunari dagokion garapena, eta bestetik, irakasleak elkarrekin bizi diren erakundea bera maila anitzetan inplikatzen duen estrategiaren garapenari dagokiena. Irizpide zabalago honi jarraiki, hainbat eta hainbat autoreren analisiek IGa esparru emankorrean kokatu dute, IG estrategiak ikuspegi holistiko eta barne-hartzaile batetik aritu behar direla defendatzen dutenean (Brew \& Boud, 1996; Gibbs, 2004; Groccia, 2010; Lynn Taylor \& Rege Colet, 2010; Steinert et al., 2006; Stes, Clement \& Van Petegem, 2007).

Alta, 90eko hamarkadaren buruan, saiakera global bezain konplexuarekin topo egiten dugu. IGaren definizioetan agerikoak diren aspektuak zehaztasun handiagoz xedatzeko asmoz, Wilkerson-ek eta Irby-k (1998) proposamen berria plazaratu eta elkarrekiko erlazioan dauden lau elementuetatik abiatzen den hurbilketa proposatzen dute. Lau «garapen» hauen elkarrekitzak erdietsiko luke IGa. Honakoak:

1. Garapen profesionala. Pertsonal akademikoa denboran zehar ibilbide laboral eta profesionalean mugitzera bideratzen diren estrategiak dira, zeinetan lan promozioa, estatusa esperientzia irabaziko diren;

2. Irakaskuntzaren garapena. Irakaskuntza hobetzeko irakasleek beharrezkoak dituzten trebetasunak ( $s k i l l s$ ) ematean arreta jartzen duten estrategiak dira;

3. Lidergoaren garapena. Kasu honetan programa akademikoen arrakasta lidergo eraginkorren eta ongi diseinatutako curriculumen araberakoak direnez, liderrek bikaintasun akademikoaren (scholarship) berezko gaitasunak garatu beharko dituzte hezkuntza planteamenduak eraginkorki ebaluatu eta ikertu ahal izateko. Horra zuzendutako estrategiak eta programak lerrokatuko lirateke maila honetan;

4. Erakundearen garapena. Irakasleriak duen hezitzaile rola indartu, irakaskuntza eta ikaskuntza sustatzeaz batera aitortza ere aurrera eramango duten politikak eta prozedurak aktibatuz eta bizitza oso- 
rako garapena bultzatzeko estrategia eta dispositiboa multzoez osatuta dago.

Euskaldun zein gaztelaniadun testuinguru akademikoetan deigarria da aztergai honek mundu anglofonotik etorritako aniztasun terminologiko zein kontzeptuala. Lehenengo bietan formazioa erabiltzen da nagusiki, irakasleriaren trebakuntza edota hobekuntza praktikak izendatzeko, instructional development kontzeptu anglofonoaren baliokidea izan zitekeena (Feixas, Fernández, Lagos, Quesada, eta Sabaté, 2013). Instructional, staff, profesional, academic, faculty, educational eta organizational development pareko terminoak euskal, espainiar zein hegoamerikar goi-mailako hezkuntza iruditegian kasik ez dira existitzen.

Aniztasun terminologiko eta kontzeptual honen sorrera ulertzea ezinbestekoa da kontzeptu hauekin lan egin ahal izateko; eta horregatik, hitzon ekoizpen testuingurua aztertzea kontzeptu amalgama honi zentzua emateko gakoa litzateke (Gosling, 2001; Lynn Taylor \& Rege Colet, 2010; Wilkerson \& Irby, 1998). Zentzu horretan, Taylor-ek eta Colet-ek (2010) seinalatzen dute, era askotako termino eta kontzeptuen presentzia praktikaren bidez sortutako ezagutzaren pausokako eraikuntza prozesuaren emaitza dela. Hein batean lekuko ekoizpen testuinguruez ari gara, zeinetan ulermen, fokapen eta baita terminologia berriak ere, kideen arteko elkarlanaz edota irakaskuntza-ikaskuntzako espezialisten (developers) laguntzaz sortutakoak diren, ikaskuntza esperientzia eraginkorragoak lortzeko helburuarekin.

Gaur egunean, badirudi joera nagusi bi daudela ñabardura terminologiko hauen guztien azpian. Nazioartean zabalduz doazen bi mugimendu, IGa modu ezberdinean interpretatzen dutenak (Fernández eta Márquez, 2014). Ekin lerro batek irakasleari emandako sostengu lanari atentzioa eman dio, faculty edo professional development - Estatu Batuen kasuan-, eta academic staff development - Australian, Europan edo Hegoafrikan, esaterako- (Collett \& Davidson, 1997; Hicks, 1999); eta bigarren ekinbideak, maila txikian (ikasgela) zein handian (instituzioa) irakaskuntza eta ikaskuntza prozesu eraginkorrak artikulatzean ipini du arreta. Azken joera hau Erresuma Batuan sorburu duen termino berri batean laburbiltzen da, educational development (Gibbs, 1996; 2013; Johnston, 1997). Azken hitz-gako hau aurrerantzean berreskuratuko dugu, baina aldez aurretik, kontzeptuaren barne eraikuntzan eragina izan duten egoera garrantzitsuenetan luzatuko gara.

\section{ESANAHIEN ERAIKUNTZA DAGOKIEN TESTUINGURUETAN: EKOIZPEN SOZIO-HISTORIKOA ETA IKERKUNTZA ZIENTIFIKOA}

IGari egotzitako termino zein esanahi ezberdinak ez dira ausazkoak. Unibertsitateetan unean uneko testuinguruaren arabera sortu diren premie- 
kin zerikusia dute (Gosling, Sorcinelli \& Chism, 2008) eta goi-mailako hezkuntzan, urteetan zehar, ekoitzi izan diren ikerketa eta teorizazioekin erlazionatutako produktu sozio-historiakoak dira. Bi analisi hauen konbinaketak kontzeptuak dituen esanahien eraikuntza prozesua nola eman den ulertzeko eta momentu bakoitzean zeri erantzuten dion konprenitzeko koordenaden mapa eskura jarriko digu.

\subsection{Kontzeptuaren hasiera eta lehendabiziko konfigurazioak: irakaskuntzaren garapena eta garapen profesionala}

Atal honetan goi-mailako hezkuntzan IGaren jatorria aztertuko dugu eta bere esanahiak, unibertsitatearen momentuko beharren arabera nola egokitu diren ikusiko dugu. Sortze unea, bereziki, unibertsitate estatubatuarretan lekutzen da, aurrerago beste herrialdeetara hedatuko zenaren ernamuinak bertan sumatzen ditugularik. Orduko bi terminoen bidez - irakaskuntzaren garapena eta garapen profesionala -, esanahien lehendabiziko dibertsifikatze prozesua nola gertatu zen ohatuko gara. Biak zein biak, lehenengo zedarritze kontzeptuala eta praktikoa ahalbidetu zuten.

Abiapuntu bat jartzearren, IGaren lehendabiziko adierazpena baimen sabatikoak izan zirela esan genezake. Sabatikoak XIX. mendean Estatu Batuetako unibertsitateetan hasi eta gerora Kanada, Erresuma Batua eta Australiara zabaldu zen praktika izan zen. Estrategia honen bidez irakasleei zegozkien irakaskuntza betekizunen liberazioa baimenduta, beste unibertsitateetan euren esperientzia eta diziplinazko ezagutza aberasteko aukera ematen zitzaien (Crosby, 1962). Tankera honetako estrategiak elitedun unibertsitateen markoan soilik inplementa zintezkeen, hau da, klase altuko ikasle kopuru txikia zuten instituzioetan hain zuzen.

Bigarren mundu gerraren ostean, unibertsitateak ikasle kopuru altuagoa jasotzen hasi ziren, arian-arian masa-instituzioak bilakatu arte. Egoera berria zen eta ikasleen aniztasuna bereziki zabaltzearen ondorioz, irakasleen irakaskuntza beharrak errotik aldatu ziren. 70eko unibertsitate ingurumari hazkor eta ezegonkor hartan, ikasle mugimendu estatubatuarrek kalitatezko hezkuntza baten aldeko kezka piztu zuten (Gaff \& Simpson, 1994). Besteak beste, irakasleak pedagogikoki gaurkotzea, curriculumaren gaineko erabakigarritasuna areagotzea eta irakasleei abian zituzteneko ikasketen inguruko feedbacka emateko aukera aldarrikatzen zuten (Ouellett, 2010). Kritika hauek guztiek ezagutzan aditua den akademikoaren arketipoa hautsi eta irakaskuntza ona diziplinaren domeinuan oinarritzen dela dioen mitoa kolokan ipini zuten. Honezkero, irakaskuntza metodo tradizionalak ez ziren nahikoak ikasle belaunaldi berri hau erakartzeko. Eta irakasleriak testuinguru berrian birsortzeari ekin behar izan zion, IG estrategiak erronka horri eusteko erreminta gisa agertuz. 
Masa-unibertsitateen eklosio momentu honetan hezkuntzara bideratutako gastua nabarmen igo zen eta gobernu organoek goi-mailako hezkuntza instituzioen gaineko kontu-errendizioa eta kontrola handitu zituzten (Groccia, 2010). Ezinbestean, hezkuntzara zuzendutako inbertsioak emaitza akademiko onen bezainbestekoa behar zuen izan (Diamond, 2005). Aldi berean, unibertsitatera ikasle berriak ekartzeko presioa areagotu eta ikerkuntzaren abangoardian egoteko finantziazio iturrien lehiakortasuna hazten joan zen (Wilkerson \& Irby, 1998). Egoera hau hobetzeko asmoz bi izan ziren hartutako erabaki instituzionalak; bata, unibertsitateak irakasleentzako garapen unitateak sortzea, eta bestea, IG programak diseinatzeko diruz hornitzea. Funtsean, ekimen hauen guztien oinarrian ideia hau gorpuzten zen: irakasle norbanakoa diziplinazko ezagutzan aditua izatearekin batera, trebetasun pedagogiko zehatzak bereganatzen joatea (Hubbard \& Atkins, 1995). Estrategia berriaren oinarrian honako elementuok hartu ziren kontutan: ikaskuntza helburu egokien definizioa, metodo zein estrategien birdiseina, ikaskuntza prozesuaren eta kurtsoaren ebaluazioari lotutako alderdiak birpentsatzea, eta orobatuz, ikaskuntza ahalbidetuko lukeen lerrokatze didaktiko eraginkorra erdiestean ipintzen zen indarra (Lynn Taylor \& Rege Colet, 2010).

Aipatutako adierak irakaskuntzaren garapenaren (instructional development) barruan sailka genitzake eta orduko eta handik aurrerako ikaskuntzaren teoria ezberdinek eragin zituzten. Hasierako momentuan, irakaskuntzaren hobekuntza trebetasun zein abilezia zehatzekin identifikatzen zituzten teoria konduktistetan oinarritutako irizpideak nagusitu ziren; gerora, irakaskuntza kontzepzio zein hurbilketen aldaketan fokua ipintzen zuten kognitibistetan oinarritutakoak heldu ziren; eta azkenik, ikasleengan ardaztutako ikaskuntza planteamendu aktiboetaraino jotzen zuten teoria sozio-konstruktibistak orokortzen joan dira (Barr \& Tagg, 1995; Trigwell, Prosser \& Waterhouse, 1999).

Erresuma Batuko unibertsitateetan antzeko ibilbidea eman zen. Irakaskuntzaren inguruko lehendabiziko publikazioak agertzearekin batera, instituzio akademikoetan profesional talde berri baten - educational developers - garrantzia hedatuz joan zen, euren eginbeharra irakaskuntza onaren garapenean irakasleari sostengua ematea zelarik (Gibbs, 2004; Gosling et al., 2008).

Aipatutako fenomeno guztiak kalitatezko irakaskuntza sustatzeko interesaren adierazle izanagatik, aldi berean ikerkuntzarekiko tentsioa ere nabaria zen. Izan ere, Estatu Batuetan, Australian, Kanadan eta Erresuma Batuan IGa unibertsitateko agendan sartu zen arren, prestigio akademikoa ez zen irakaskuntza onean zentratzen, ikerkuntzan eta artikulu zientifikoen ekoizpenean baizik. Unibertsitatekoak ez diren beste hezkuntza mailetan ez bezala, goi-mailako hezkuntzan IGak ez ditu pertsona akademikoen garapen profesionalak beharko lituzkeen esanahi guztiak barnebiltzen. Adibide bat ekartzearren, Centra-k (1978) unibertsitateko irakasleria sostengatzen 
duten estrategiak, irakasleek betetzen dituzten rol guztietara zabaltzea azpimarratzen du. Hots, irakaskuntza, ikerkuntza, administrazioa, idazkuntza akademikoa eta ibilbide profesionalaren kudeaketa. Beste hitzekin esanda, garapenaren enfasia irakasle onak lortzearekin batera, unibertsitatean ibiltarte profesionalerako jarraibideak ematean ere ipiniko bada. Hartara, ibilbide laborala eta profesionala garatuko duen pertsonal akademikora hedatzen da ikuspegia, horrela jardun ezkero, denboran zehar promozionatzen eta estatusa zein esperientzia irabazten joango dena (Kreber, 2002).

Iragate honetan Ernest Boyer-en (1990) ekarpenak berebiziko garrantzia izan zuen. Autore honek unibertsitate estatubatuarretako bilakaeraren azterketa historikoan oinarri hartuta XX.mendearen bukaeran unibertsitateetan nagusi zen ikertzaile rola murriztailea jomugan jarri eta kritikatu zuen. Akademikoa izatea zertan datzan aztertu eta proposamen integrala aurreratu zuen, bikaintasun akademikoaren (scholarship) lau dimentsio proposatuz. Haietako bat irakaskuntzaren bikaintasun akademikoa (scholarship of teaching) deritzon kontzeptua dugu, artikulu honen bukaerako atalean aztertuko dugunez, britainiar edota australiar kualifikazio markoetako irakaskuntza eta ikaskuntza maila zorrotzenekin identifikatzen den gaitasuna.

\subsection{Irakasleriaren garapenerako estrategien inpaktua neurtzen goi-mailako hezkuntzan: enfasi instituzionalak eta erakundekoak}

Kontzeptuaren eboluzioa ulertu ahal izateko IGko estrategiek duten inpaktuaren inguruan egindako ikerketetatik eratorritako aztertu beharra dagoela uste dugu. Arestian aipatu legez, IGerako zerbitzuen abiaraztea unibertsitateen hazkundearekin batera eman zen, eta ez hori bakarrik, baita goi-mailako hezkuntza diruz laguntzea zalantzan jartzen zen unean ere. Inguruabar honetan, IGaren inpaktua edo eraginkortasuna demostratzeko galdegiten da, hau da, estrategia hauek kalitatea noraino hobetzen duten azaldu beharra nagusitzen da. Ataka honetan ikertzeko beharra bi zailtasunei aterabidea emateko azaltzen da: lehenengoa, irakaskuntza-ikaskuntza prozesuak sakonki hobetzeko zailtasunari, eta bigarrena, eraginkortasuna ebidentzian oinarritzeko zailtasunari (Brew, 2007; Chalmers, 2012; Feixas, Fernández, Lagos eta Sabaté, 2015; Gibbs \& Coffey, 2004; Kirkpatrick, 1994; Parsons, Hill, Holland \& Willis, 2012; Steinert et al., 2006; Stes et al., 2007; Weimer \& Lenze, 1997).

Halabeharrez, 1994an Kirkpatrick-en azterlanaren eskutik zailtasun horiek gainditzeko proposamen aitzindarietako bat dator. Egile honek IGaren inpaktua neurtzeko ebaluazio sistema bat proposatzen du lau maila ezberdinetako hezkuntza emaitzen arabera: a. Erreakzioak (asebetetzea); b. Ikaskuntza (jarreretan, trebetasunetan eta ezagutzetan izandako aldaketak); d. Jokabidea (ikasitakoa praktikara eramateko gaitasuna eta praktikaren aldaketa); e. Emaitzak (aldaketa maila instituzionalean zein erakundekoan 
eta ikasleen ikaskuntzan). Lehendabiziko hiru inpaktu-mailek (a, b, d) IGak norbanakoan izandako eragina aztertzen duten bitartean, azkenekoak (e) urrats bat harago eman eta aldaketa, geruza instituzionalean eta erakundekoan kokatzen du. Maila anitzeko ebaluazio proposamen honek izaera globala eta konplexua duten IG ikuspegien inpaktua neurtzeko aukera ematen du, esaterako, lehenengo atalean jorratu dugun Wilkerson eta Irby-rena, (1998) kasu.

Gibbs-en eta Coffey-ren (2004) azterlanak beste mugarri esanguratsuetakoa ezarri zuen IG estrategien inpaktuaren ikerketari dagokionean. Graham Gibbs alor honetan ospe handia duen irakasle eta ikerlari britainiarra da eta 2004ko azterlanean, analisiaren ekuazioan maila indibiduala sartzeaz batera, ikasleen ikaskuntza barneratu eta azterketaren eragina instituzio osora zabaltzearen aldeko hautua egiten du. Planteamendu hau ez da nolanahikoa, bere emaitzetatik ondoriozta baitaiteke, unibertsitatea modu globalean aldatu ahal izateko, ez dela nahikoa irakasleen praktika indibidualak aldatzera bideratutako estrategiekin bakarrik. Haratago joatea beharrezkoa da, Gibbs-en eta Coffey-ren esanetan, eta bada dagoeneko inpaktuaren inguruko azterketen proposamenetan agertzen diren maila ezberdinak aintzat hartzeko premia ere bai.

Inpaktuari buruzko ikerketek, hein handi batean, enfasia maila indibidualean ez beste mailetan kokatzen zuten IGaren definizioak babesten dituzte. Indibiduala esaten denean, izan trebetasun teknikoen entrenamendua, izan kontzepzio zein hurbilketen aldaketa prozesuak edota izan prozesu sozio-konstruktibistak. Eta aldi berean, ikerketok garapen profesionala eta akademikoarekiko arreta ikusaraztearekin batera, erakundearekin, instituzioarekin edota kulturarekin erlazionatutako maila konplexuagoetara iragaten dira. Beste modu batera esanda, IGak duen inpaktuaren inguruko ikerkuntza detonatzailea izan da maila anitzeko aldaketari ateak irekitzeko.

Irekierarekin batera, IGerako estrategien inpaktua espero daitekeen maila ezberdin hauen formulazioak, izaera teoriko zein praktikodun erronkak planteatzen ditu. Izan ere, indibiduoak irakasle onak bilakatzeaz gaindi, desafioek irakaskuntza-ikaskuntzari bideratutako azpiegituretan, markoetan eta erakundeetan atentzioa fokatuko dituzten ikuspegi zabalak bultzatzeko beharra esplizituki adierazten dutelako (Ceylan, Fiehn, Paetz, Schworm \& Harteis, 2011; Urban \& Meister, 2010). Ezbairik gabe, inpaktuaren ebaluazioa maila hauetan kokatzeak kontzeptu bera zalantzan jartzea ekarri du eta irakaskuntzaren garapenaz zein garapen profesionalaz haratago doazen beste esanahiak eztabaidatzera eraman du. Autoreak, hortaz, urrats teoriko berria emateko prest zeuden, educational development edo euskarara ekarria, hezkuntzaren garapena. 


\subsection{Hezkuntzaren garapena: sintesi berri bat?}

Arestian aipatu dugun moduan, mundu osoko unibertsitateek langai duten bi fokuen arteko tentsioa modu ezberdinetara gauzatzen doa testuinguru bakoitzean - batetik, irakasleriari sostengua ematea irakasle, akademiko edota profesional gisa, eta bestetik, maila txikian zein handian eraginkorrak diren irakaskuntza-ikaskuntza prozesuak eramatea-. Adibidez Europari begiratuz gero, joera indartsuena berriki educational development edo hezkuntzaren garapena izendatu den mugimenduaren alde dagoela dirudi (Gibbs, 1996; 2013; Johnston, 1997), areago, azken hamarkadetan goi-mailako europar hezkuntzaren eremuaren (GMEHE) eraikuntza baliatu dituzten politikekin lagunduta. Kontzeptu honen eklosioan, arrazoi ekonomikoak egon badira; espreski, unibertsitateei zuzendutako kontu-errendizio eta izaera lehiakorra duten eskakizunei lotutako egokitzapenak. Baina hauen gainetik, aldaketari eusten dioten bi idei nagusi azaleratzen dira, jarraian hurrenez hurren zirriborratuko ditugunak. Lehenengo ideia, ikaskuntza bera irakaskuntza-ikaskuntza prozesuen muinean kokatzean datza; eta bigarrena, unibertsitatea ikasten duen erakundea bezala ezaugarritzean.

Norbaitek esan dezake irakaslearengan eta bere diziplinan arreta jartzetik urrundu eta, aldiz, ikasleen ikaskuntzan ardazten diren ereduak ez direla nobedade. Halere, azken urteotan goi-mailako hezkuntza politiken harira ikaskuntzari eman zaion nagusitasuna erlatiboki berria da. Hasiera batean, IGaren sorreraz hitz egitean, estrategien helburua irakaslean modu indibidualean eragitea zela aztertu dugu. Hala izanik, ondoren egin diren ikerketa ugarik (Barnett, 1994; Barr \& Tagg, 1995; Clifford, 1999; Gibbs, 2013; Prosser \& Trigwell, 1999; Zimmerman, 2002), interesa ikasleen ikaskuntzara birbideratu dute arreta, berau gabe irakaskuntza zentzugabea dela argudiatuz.

Baina ikaskuntzan geroz eta zentratuago egoteaz gain, gutxika, indibiduoez gaindi, instituzionalagoa dena zilegitasuna irabazten ari da, unibertsitateentzako ekinbide interesgarria izan daitekeelakoan. Laburrean, ezagutzan eta ikaskuntzan oinarritzen diren erakundeen bereizgarriaz ari gara (Senge, 2006). Gurea bezalako krisi eta aldaketa garaian ere, giza kapitala ezinbestekoa duen ikaskuntza ingurunea eraikitzearen garrantzia lehenesten duen erakundea.

Azken batean, aldaketari lotutako bi ideia nagusi hauek goi-mailako hezkuntzako IGaren eremuan sintesi berri batean elkartzen direla ematen du. Orain bai, praktika errealen analisi zorrotz batek diskurtsoek adierazten dutenarekin bat ez datozela argi erakusten du. Gibbs-ek (2004) hezkuntzaren garapenean tradizio luzea duen testuinguru batetik, zehazki Erresuma Batutik, datozen diskordantzia hauek azaltzeko ahalegina egiten du. Ondorioztatu zuenez, irakasleen esfortzu indibidual guztiak batuta ere - erabateko konpromisoa eta gaitasuna eduki arren - , testuinguru aldakorrari aurre egiteko beharrezkoak ziren tamainazko aldaketak ezin daitezke lortu. Honen ordez, estrategia instituzional koherentea beharko litzateke, zeinean 
irakaskuntzan eginbeharreko hobekuntzek lekua edukiko zuketen eta ekintza marko batean behar bezala jasoak egongo ziratekeen (Gibbs, 2004:17). Beste modu batean adierazita, irakasleriaren esfortzu txiki eta isolatuen metaketak ez du aldaketa globalak duen eragin garrantzitsua ziurtatzen, ez eta azken emaitza gisa ikaskuntzara bideratutako unibertsitatea eraikitzen ere.

Honen harira, hamaika dira komunitate zientifiko akademikoak unibertsitatean irakaskuntza eta ikaskuntza hobeki neurritzeko saiakerak. Gibbsek $(2009,2013)$ azken hamarkadetan irakaskuntzatik ikaskuntzarako iraganbidean eman izan diren mugimenduak modu sintetikoan konpilatzen ditu (ikus 2. taula). Antzeman daitekeenez, hezkuntzaren garapena ikuspegi sinple eta konpromiso gutxikoetatik globalagoak eta konplexuagoak direnetara mugitzen joan da, izan ere, trantsizio hori gertatu da fokua indar handiagoz ikaskuntzan ipini denean.

2. taula

Unibertsitatean irakaskuntza

eta ikaskuntza garatzeko egin diren esfortzuen sintesia

\begin{tabular}{|c|c|}
\hline Irakaskuntzan oinarritutakoak & Ikaskuntzan oinarritutakoak \\
\hline Fokua ikasgelan & $\begin{array}{l}\text { Fokua ikaskuntza ingurunean, } \\
\text { ebaluazioan (assessment) eta ezaugarri } \\
\text { sozialetan }\end{array}$ \\
\hline Fokua irakasle norbanakoetan & $\begin{array}{l}\text { Fokua lidergoan, taldeetan, graduetan, } \\
\text { sailetan eta instituzio osoan }\end{array}$ \\
\hline Txikia, sinplea, osagai indibiduala & $\begin{array}{c}\text { Zabala, konplexua, maila anitzetan eta } \\
\text { modu askotara elkar konektatutako } \\
\text { osagaiak }\end{array}$ \\
\hline Bananduak, esfortzu isolatuak & Integratuak, lerrokatutako esfortzuak \\
\hline Kalitatearen segurtatzea & Kalitatearen hobekuntza \\
\hline Teoriarik gabekoa & Kontzeptuekin eraikia, teorizatua \\
\hline Esperientzien bidezkoa & Enpirikoa, ebidentzietan oinarritutakoa \\
\hline Oinarri psikologikoa & Oinarri sozial eta kulturala \\
\hline Amateur & Profesionala \\
\hline $\begin{array}{c}\text { Antolakuntza periferikoa eta beste } \\
\text { ekimenak bultzatuz }\end{array}$ & $\begin{array}{c}\text { Norabide berrietara bideratuta praktika } \\
\text { berriak engaiatuz }\end{array}$ \\
\hline Testuingurutik at & $\begin{array}{c}\text { Testuinguruarekiko menpekoa } \\
\text { eta sentikorra }\end{array}$ \\
\hline
\end{tabular}

Iturria: Gibbs (2009:8-9). 
Beraz, hezkuntzaren garapena izendapenaren bidez, maila lokaletatik maila global zein instituzionaletaraino irakaskuntza-ikaskuntza prozesu eraginkorrak artikulatzea proposatzen duen integrazio moduko ideiaz ariko ginateke (Badley, 1998; Debowski, 2011; Euler, 2015; Gibbs, 1996; Land, 2004; Lynn Taylor \& Rege Colet, 2010); unibertsitatea modu orokorrean aldatzea ahalbidetuko lukeena. Horregatik, hezkuntzaren garapenak, goimailako hezkuntzan ematen diren irakaskuntza eta ikaskuntza prozesuen helburuak planteamendu zabalagoetatik eztabaidatzearekin du zerikusia, diskusio honetara curriculumaren izaera eta hezkuntzaren testuinguru politikoa zein soziala gerturatuz (Gosling, 2001).

Laburbilduz, hezkuntzaren garapenak ez du soilik irakaskuntza-ikaskuntza, curriculuma eta ebaluazioa «sostengatu», «bultzatu», «garatu» edota «hobetzeko» xedea; baizik eta, goi-mailako hezkuntzari izaera akademikoa emateko xedea ere, berau berrikusiz, analizatuz eta ikertuz (Badley, 1998). Maila txikian zein handian irakaskuntza-ikaskuntza prozesu eraginkorrak bultzatzearen aldeko apustua egiteak, irakasle hobeak lortzea suposatzen du; baina aldi berean, baita unibertsitateko ibilbide profesionalarentzako jarraibideak ematea ere. Hau da, irakasleek bete beharreko rol guztiei arreta emanez eta batetik bestera igarotzeko betekizunei eta aurreikusitako mailei gertutik begiratuz.

\section{EZTABAIDA ETA AZKEN GOGOETAK}

Denboran zehar IGaren kontzeptuan eman diren aldaketen eta jarraipenen inguruko analisitik burutazio argia erator daiteke. Izatez, nazioartean unibertsitateko eremu akademikoa, hezkuntzaren kalitatea hobetze aldera irismen ezberdinetako IG proposamenen agertokia izan dela eta egun ere, badela. Gauzak honela, logika ezberdinetatik eraikiak izan baina osagarriak diren bi indar-guneetara bideratu nahiko genuke eztabaida. Biak ala biak, ikaskuntzaren garapenean eraginkorragoak diren unibertsitateen oinarriak jartzen baitituzte.

Inpaktuaren aztergaia IGaren alorrean eztabaida luzea eragin duen lehendabiziko elementua izan da: zein da garapen-estrategien egiazko efektua?, nola izan gaitezke eraginkorrak erakunde zein maila instituzionalean eta areago, ikasleen ikaskuntza prozesuan?, eta eraginkortasuna neurtzea posiblea balitz, nola sistematizatu? IGaren estrategiak inpaktuaren ikusmiratik ikertzeak kontzeptu beraren ulermen konplexuagoa ahalbidetu du. Arean ere, unibertsitateko formazioaren kalitatea irakasleari dagokion irakaskuntza arazo bat besterik ez deneko ikuspegi sinplistarekin apurtzen baitu. Inpaktuak neurtua eta berretsita behar duela izan ulertzearekin batera, maila ezberdinak ebidentziaz janzteko beharra ikustera ere iritsi gara. Eboluzio bide horretan kokatzen da, norbanakoa, erakundea, instituzioa eta kul- 
tura konektatzen dituen hezkuntzaren garapena bezalako kontzeptu konplexua eta zehatza.

Bigarren eztabaidagaiak garapen profesionalaren eta akademikoaren inguruan agerikoa den kezka mahai gaineratzen du. Nahitaez, unibertsitateko irakasleen ibilbidean zehar landu beharrekoak, eta azkenean, irakasleriaren kualifikazio markoak deiturikoetan amaitu duen ardura (Chalmers, 2007). Boyer-ek (1990) adierazi zuen bezala, honek esan nahi du unibertsitateko irakasleriak bete beharreko rol akademikoak ezinbestean birpentsatzeko premia dagoela, baldin eta goi-mailako hezkuntza kalitatean maila zainduena lortu nahi badugu. Eta zalantzarik ez da, irakaskuntza rola indartzeak irakaskuntza eta ikaskuntza lan akademikoaren profesionalizazioa (Scholarship of Teaching and Learning) sustatzea dakar, gaur egunean unibertsitateetako agendetan erronka gakoa bilakatu dena.

Irakasleriaren garapena edo formazioa deritzogunaren birformulazio edota berrinterpretazio hauek, hezkuntzaren garapena bezalako kontzeptuak bereganatzera zuzendu beharko gintuzketen. Finean, kalitatearen hobekuntza, maila ezberdinetan aktibatzen diren interbentzio konplexu eta sinergikoen ondorio dela ulertzen duten kontzeptu berriak. Horregatik esaten dugu, goi-mailako hezkuntza instituzioak ikuspegi holistiko batetik pentsatu, diseinatu eta ebaluatutako estrategiak garatzeko prest egon behar direla. Hala ere, errealitateak ez du hori erakusten, eta oraindik orain bide luzea geratzen da ibiltzeke. Zentzu horretan irakaskuntzaren eta ikaskuntzaren profesionalizazioan espazioak ireki ditzaketen bideak zirriborratzen doaz: ikasgelako ikerketaren bidez edota ikerketa aktiboa dela medio. Biek elkarrizketa kritikoa gauzatzeko aukerak irekitzen dituzte. Batetik, irakaskuntza-ikaskuntzaren debatea sailetan eta eszenatoki instituzionalean kokatuz eta bestetik, ikaskuntza ikerketaren, irakaskuntzaren, profesionalizazioaren eta elkarrizketaren artean dagoen lotura kritiko moduan bultzatuz (Badley, 1998; Muñoz eta Garay, 2015). Gainera, gaur egun euren lekua bereganatzen ari diren irakasleriaren kualifikazio markoak (Chalmers, 2007; Chalmers \& Gardiner, 2015; Euler, 2015; Margalef eta Álvarez, 2005; Tigelaar, Dolmans, Wolfhagen \& Van der Vleuten, 2004) kalitatezko irakaskuntza-ikaskuntza prozesuak garatzera bideratutako irizpideekin eraikiak izan beharko lirateke, besteak beste, bikaintasunaren integrazioa, ikerketa, irakaskuntzarako eta ikasleen ikaskuntzarako sostengua diren ekintza profesionalak tankerako erakusleak.

Azken ondorio modura esan behar da, unibertsitateen irakaskuntza-ikaskuntza ahalmena modu global, instituzional eta holistikoan garatzera zuzendutako ekintza eta zereginak oraindik hastapeneko garapen fasean aurkitzen direla (Fernández eta Márquez, 2014). Alta, elementu hauek guztiak aldaketan oinarritutako estrategia instituzional eta koherentean integratuko lituzketen pentsamolde eta ekinbide berriak - inoiz baino - beharrezkoak 
dirudite. Proposamen horien bidez, irakaskuntzari dagozkion hobekuntzak apailatzea eta irakasleak akademiko (scholar) edo irakaskuntzaren profesional gisa jardutea egingarria izan dadin (Bland et al., 1990; Smith, 2001).

\begin{abstract}
Faculty development is recognized as a relevant factor for improving the quality of education in higher education institutions. However, behind this term different conceptions and practices are hiding. This article aims to analyze the changes and continuities of this concept over time and to understand deeply the complexity of their meanings, for which we will approach the construction of these meanings in their socio-historical contexts of production and scientific research. This perspective of analysis allows us to conclude that it has been moving from an approach oriented to supporting teachers in their development as teachers, professionals and/or academics, towards another, focused on promoting effective teaching and learning processes at micro and macro level. These challenges highlight the need to foster broader visions that, beyond teachers, focus on organizations, frameworks, and infrastructures that target teaching and learning.
\end{abstract}

Keywords: educational quality, instructional improvement, educational development, learning, organizational change, higher education.

El desarrollo docente es reconocido como un factor relevante para la mejora de la calidad educativa en las instituciones de educación superior. No obstante, detrás de este término se esconden concepciones y prácticas diferentes. Este trabajo pretende analizar los cambios y continuidades de este concepto a lo largo del tiempo y comprender profundamente la complejidad de sus significados, para lo cual abordaremos la construcción de estos significados en sus contextos de producción socio-histórica y de investigación científica. Esta perspectiva de análisis nos permite concluir que se ha ido transitando desde un enfoque orientado a apoyar al profesorado en su desarrollo como docente, profesional y/o académico, hacia otro, enfocado a favorecer procesos de enseñanza-aprendizaje efectivos a nivel micro y macro. Estos desafios explicitan la necesidad de fomentar visiones más amplias que, más allá del profesorado, fijen la atención en las 
organizaciones, los marcos y las infraestructuras que se dirigen a la enseñanza-aprendizaje.

Palabras clave: calidad educativa, mejora instruccional, desarrollo educacional, aprendizaje, cambio organizativo, educación superior.

Le développement du corps professoral est reconnu comme un facteur pertinent pour améliorer la qualité de l'enseignement dans les établissements d'enseignement supérieur. Cependant, derrière ce terme, différentes conceptions et pratiques se cachent. Cet article a pour objectif d'analyser les changements et les continuités de ce concept au fil du temps et de comprendre profondément la complexité de leurs significations, pour lesquelles nous aborderons la construction de ces significations dans leurs contextes socio-historiques de production et de recherche scientifique. Cette perspective d'analyse nous permet de conclure qu'elle est passée d'une approche orientée vers le soutien des enseignants dans leur développement en tant qu'enseignants, professionnels et / ou universitaires, vers une autre, axée sur la promotion des processus d'enseignement et d'apprentissage efficaces au niveau micro et macro. Ces défis mettent en évidence la nécessité de promouvoir des visions plus larges qui, au-delà des enseignants, mettent l'accent sur les organisations, les cadres et les infrastructures qui ciblent l'enseignement et l'apprentissage.

Mots-clé: qualité de l'éducation, amélioration de l'enseignement, le développement de l'éducation, l'apprentissage, le changement organisationnel.

\section{ERREFERENTZIAK}

Badley, G. (1998). Making a case for educational development in times of drift and shift. Quality Assurance in Education, 6(2), 64-73.

Barnett, R. (1994). The limits of competence: Knowledge, higher education and society. ERIC.

Barr, R. B. \& Tagg, J. (1995). From teaching to learning - A new paradigm for undergraduate education. Change: The Magazine of Higher Learning, 27(6), 12-26.

Bland, C. J., Schmitz, C. C., Stritter, F. T., Henry, R. C. \& Aluise, J. J. (1990). Successful faculty in academic medicine. New York: Springer Publishing Company.

Bligh, J. (2005). Faculty development. Medical Education, 39(2), 120-121.

Boyer, E. L. (1990). Scholarship reconsidered: Priorities of the professoriate. New Jersey: Princeton University Press. The Carnegie Foundation for the Advancement of Teaching. 
Brew, A. (2010). Transforming academic practice through scholarship. International Journal for Academic Development, 15(2), 105-116.

- (2007). Evaluating academic development in a time of perplexity. International Journal for Academic Development,12(2), 69-72.

Brew, A. \& Boud, D. (1996). Preparing for new academic roles: An holistic approach to development. The International Journal for Academic Development, 1(2), 17-25.

Centra, J. A. (1978). Types of faculty development programs. The Journal of Higher Education, 49(2), 151-162.

Ceylan, F., Fiehn, J., Paetz, N., Schworm, S. \& Harteis, C. (2011). Die auswirkungen des bologna-Prozesses-Eine expertise der hochschuldidaktik. In S. Nickel (Hg.), Der Bologna-Prozess Aus Sicht Der Hochschulforschung (pp. 106122). Gütersloh: Bundesministerium fur Bildung und Forschung.

Chalmers, D. (2012). Identification and implementation of the indicators and measures of the impact on teaching preparation programs in higher education (TPP impact). Centre for the Advancement of Teaching and Learning, ([On line])

- (2007). A review of Australian and international quality systems and indicators of learning and teaching. Carrick Institute for Learning and Teaching in Higher Education, 1(2).

Chalmers, D. \& Gardiner, D. (2015). An evaluation framework for identifying the effectiveness and impact of academic teacher development programmes. Studies in Educational Evaluation, 46, 81-91.

Clifford, V. A. (1999). The development of autonomous learners in a university setting. Higher Education Research y Development, 18(1), 115-128.

Collett, P. \& Davidson, M. (1997). Renegotiating autonomy and accountability: The professional growth of developers in a South African institution. The International Journal for Academic Development, 2(2), 28-34.

Crosby, E. W. (1962). The origin and early history of sabbatical leave. AAUP Bulletin, 48(3), 253-256.

Day, C. (2005). Formar docentes: Cómo, cuándo y en qué condiciones aprende el profesorado. Madril: Narcea Ediciones.

Debowski, S. (2011). Emergent shifts in faculty development. To Improve the Academy: Resources for Faculty, Instructional, and Organizational Development, 30, 306-324.

Declaration, B. (1999). The European higher education area. Joint Declaration of the European Ministers of Education, 19, 24-69.

Diamond, R. M. (2005). The institutional change agency: The expanding role of academic support centers. To Improve the Academy, 23, 24-37.

Euler, D. (2015). Mejorar las competencias docentes del profesorado universitario es necesario, ipero la innovación sostenible requiere algo más! Educar, 51(1), $149-165$.

Eurydice. (2007). Focus on the structure of higher education in europe: National trends in the bologna process-2006/07. Brussels, Belgium: Eurydice European Unit.

Feixas, M., Fernández, A., Lagos, P., Quesada, C. eta Sabaté, S. (2013). Factores condicionantes de la transferencia de la formación docente en la universidad: un estudio sobre la transferencia de las competencias docentes. Infancia Y Aprendizaje, 36(3), 401-416. 
Feixas, M., Fernández, I., Lagos, P. eta Sabaté, S. (2015). Modelos y tendencias en la investigación sobre efectividad, impacto y transferencia de la formación docente en educación superior. Educar, 51(1), 081-107.

Fell, T., Haines, I. \& Denicolo, P. (2009). The bologna process and beyond: Implications for postgraduate education. SRHE.

Fernández, I. eta Márquez, D. (2014). Formación docente ¿un concepto en crisis? Situación actual y tendencias emergentes en las universidades del estado español. In C. Monereo (Ed.), Enseñando a enseñar en la universidad. Sistemas alternativos de formación del profesorado. Parte 3. Prospectiva: El futuro de la formación del profesorado (pp. 251-292). Octaedro.

Francis, J. B. (1975). How do we get there from here? Program design for faculty development. The Journal of Higher Education, 46(6), 719-732.

Gaff, J. G. (1975). Toward faculty renewal. San Francisco: Jossey-Bass.

Gaff, J. G. \& Simpson, R. D. (1994). Faculty development in the United States. Innovative Higher Education, 18(3), 167-176.

García-Gómez, S. (1999). El desarrollo profesional. análisis de un concepto complejo. Revista de Educación N. . 318. Economía De La Educación, (318), 175187.

Gibbs, G. (2013). Reflections on the changing nature of educational development. International Journal for Academic Development, 18(1), 4-14.

- (2009). Developing students as learners-varied phenomena, varied contexts and a developmental trajectory for the whole endeavour. Journal of Learning Development in Higher Education ISSN, 31(1), 1-12.

- (2004). Mejorar la enseñanza y el aprendizaje universitario mediante estrategias institucionales. Educar, 3(33), 11-30.

- (1996). Supporting educational development within departments. The International Journal for Academic Development, 1(1), 27-37.

Gibbs, G. \& Coffey, M. (2004). The impact of training of university teachers on their teaching skills, their approach to teaching and the approach to learning of their students. Active Learning in Higher Education, 5(1), 87-100.

Gosling, D. (2001). Educational development units in the UK-what are they doing five years on? International Journal for Academic Development, 6(1), 74-90.

Gosling, D., Sorcinelli, M. D. \& Chism, N. (2008). The future of faculty/educational development: An international perspective. Paper presented at the Biennial Meeting of the International Consortium for Educational Development Conference, Salt Lake City, UT.

Groccia, J. (2010). Why faculty development why now. In A. Saroyan \& M. Frenay, (Eds.) Building teaching capacities in higher education: A comprehensive international model. (pp. 1-20) Sterling, VA: Stylus.

Hanbury, A., Prosser, M. \& Rickinson, M. (2008). The differential impact of UK accredited teaching development programmes on academics' approaches to teaching. Studies in Higher Education, 33(4), 469-483.

Hargreaves, A. (2003). Teaching in the knowledge society: Education in the age of insecurity. Teachers College Press.

Hicks, O. (1999). Integration of central and departmental development-reflections from Australian universities. The International Journal for Academic Development, 4(1), 43-51. 
Hubbard, G. T. \& Atkins, S. S. (1995). The professor as a person: The role of faculty well-being in faculty development. Innovative Higher Education, 20(2), 117-128.

Imbernón, F. (1994). La formación y el desarrollo profesional del profesorado: hacia una nueva cultura profesional. Bartzelona: Graó.

Johnston, S. (1997). Educational development units: Aiming for a balanced approach to supporting teaching. Higher Education Research and Development, 16(3), 331-342.

Jonassen, D. H. (1999). Designing constructivist learning environments. Instructional Design Theories and Models: A New Paradigm of Instructional Theory, 2, 215-239.

Kirkpatrick, D. K. (1994). Evaluating training programs: Four levels. San Francisco: Berrett-koehler.

Knapper, C. (2003). Editorial: Three decades of educational development. International Journal for Academic Development, 8(1-2), 5-9.

Kolb, A. Y.\& Kolb, D. A. (2005). Learning styles and learning spaces: Enhancing experiential learning in higher education. Academy of Management Learning y Education, 4(2), 193-212.

Kreber, C. (2002). Teaching excellence, teaching expertise, and the scholarship of teaching. Innovative Higher Education, 27(1), 5-23.

Land, R. (2004). Educational development: Discourse, identity and practice. United Kingdom: McGraw-Hill Education.

Lewis, K. G. (1996). Faculty development in the United States: A brief history. The International Journal for Academic Development, 1(2), 26-33.

Lynn Taylor, K. \& Rege Colet, N. (2010). Making the shift from faculty development to educational development. In A. Saroyan \& M. Frenay (Eds.) Building Teaching Capacities in Higher Education: A Comprehensive International Model. Sterling, Virginia: Stylus.

Madinabeitia, A. eta Fernández, I. (2015). Iraupen luzeko irakasleriaren garapenaren eraginkortasuna: irakasleriaren kontzepzioetan, hurbilketan eta kultura instituzionalean. Tantak, 27(1).

Macdonald, R. (2002). Educational development: Research, evaluation and changing practice in higher education. In R. Macdonald \& J. Wisdom (Eds.) Academic and Educational Development: Research, Evaluation and Changing Practice in Higher Education (pp. 3-13). London: Kogan Page.

Marcelo, C. eta Vaillant, D. (2010). Desarrollo profesional docente: ¿Cómo se aprende a enseñar? Madril: Narcea Ediciones.

Margalef García, L. eta Álvarez Méndez, J. M. (2005). La formación del profesorado universitario para la innovación en el marco de la integración del espacio europeo de educación superior. Revista De Educación, (337), 51-70.

McLean, M., Cilliers, F. \& Van Wyk, J. M. (2008). Faculty development: Yesterday, today and tomorrow. Medical Teacher, 30(6), 555-584.

Muñoz Martínez, M. eta Garay Garay, F. (2015). La investigación como forma de desarrollo profesional docente: Retos y perspectivas. Estudios pedagógicos (Valdivia), 41(2), 389-399.

Norton, A., Sonnemann, J. \& Cherastidtham, I. (2013). Taking university teaching seriously. Grattan Institute. 
Ouellett, M. L. (2010). Overview of faculty development. In Kay J. Gillespie \& Douglas L. Robertson (Eds.) A Guide to Faculty Development (pp. 3-20). San Francisco: Jossey-Bass.

Parsons, D., Hill, I., Holland, J. \& Willis, D. (2012). Impact of teaching development programmes in higher education. The Higher Education Academy: HEA Research Series.

Professional and Organizational Network in Higher Education (POD). (2007). What is faculty development? 2016ko azaroaren 10ean berreskuratua: http:// www.podnetwork.org/development.htm

Prosser, M. \& Trigwell, K. (1999). Understanding learning and teaching: The experience in higher education. Buckingham: SRHE and Open University Press.

Ramsden, P. (2003). Learning to teach in higher education. New York: Routledge.

Senge, P. M. (2006). The fifth discipline: The art and practice of the learning organization. Broadway Business.

Sheets, K. J. \& Schwenk, T. L. (1990). Faculty development for family medicine educators: An agenda for future activities. Teaching and Learning in Medicine: An International Journal, 2(3), 141-148.

Smith, M. (2001). Reforming teacher education: Competing agendas. Journal of Teacher Education, 52(4), 263-263.

Sorcinelli, M. D., Austin, A. E., Eddy, P. L. \& Beach, A. L. (2005). Creating the future of faculty development: Learning from the past, understanding the present. Bolton, MA.

Steinert, Y. (2000). Faculty development in the new millennium: Key challenges and future directions. Medical Teacher, 22(1), 44-50.

Steinert, Y., Mann, K., Centeno, A., Dolmans, D., Spencer, J., Gelula, M. \& Prideaux, D. (2006). A systematic review of faculty development initiatives designed to improve teaching effectiveness in medical education: BEME guide no. 8. Medical Teacher, 28(6), 497-526.

Stes, A., Clement, M. \& Van Petegem, P. (2007). The effectiveness of a faculty training programme: Long-term and institutional impact. International Journal for Academic Development, 12(2), 99-109.

Taylor, R. \& Canfield, P. (2007). Learning to be a scholarly teaching faculty: Cultural change through shared leadership. Transforming a University: The Scholarship of Teaching and Learning in Practice, 21(3), 233-247.

Tigelaar, D. E., Dolmans, D. H., Wolfhagen, I. H. \& Van der Vleuten, P.M. (2004). The development and validation of a framework for teaching competencies in higher education. Higher Education, 48(2), 253-268.

Trigwell, K., Prosser, M. \& Waterhouse, F. (1999). Relations between teachers' approaches to teaching and students' approaches to learning. Higher Education, 37(1), 57-70.

Urban, D. \& Meister, D. M. (2010). Strategien der professionalisierung in der hochschuldidaktik. Zeitschrift Für Hochschulentwicklung.

Välimaa, J. \& Hoffman, D. (2008). Knowledge society discourse and higher education. Higher Education, 56(3), 265-285. 
Weimer, M. \& Lenze, L. F. (1997). Instructional interventions: A review of the literature on efforts to improve instruction. Effective Teaching in Higher Education: Research and Practice, 205-240.

Wilkerson, L. \& Irby, D. M. (1998). Strategies for improving teaching practices: A comprehensive approach to faculty development. Academic Medicine, 73(4), 387-396.

Zimmerman, B. J. (2002). Becoming a self-regulated learner: An overview. Theory into Practice, 41(2), 64-70. 